Check for updates

Cite this: RSC Adv., 2018, 8, 23757

Received 30th March 2018

Accepted 13th June 2018

DOI: $10.1039 / \mathrm{c} 8 \mathrm{ra0} 2727 \mathrm{~g}$

rsc.li/rsc-advances

\section{Characterization of key aroma compounds in Meilanchun sesame flavor style baijiu by application of aroma extract dilution analysis, quantitative measurements, aroma recombination, and omission/addition experiments}

\author{
Jinyuan Sun, ${ }^{\text {ab }}$ Qinya Li, ${ }^{\text {ab }}$ Siqi Luo, ${ }^{\text {ab }}$ Jinglin Zhang, (D) ab Mingquan Huang, (D) *ab \\ Feng Chen, (D) ${ }^{c}$ Fuping Zheng, ${ }^{\mathrm{ab}}$ Xiaotao Sun ${ }^{\mathrm{ab}}$ and Hehe Li ${ }^{\mathrm{ab}}$
}

\begin{abstract}
The aroma components in Meilanchun sesame flavor style baijiu were identified by aroma extract dilution analysis (AEDA), quantitative analysis, aroma active compound recombination, and omission/addition experiments. 92 components in Meilanchun were identified. Among them, 47 odor active compounds were further confirmed by GC-MS/O with aroma extract dilution analysis (AEDA). Ethyl pentanoate, 3methy-1-butanol, methional, ethyl 3-phenylpropanoate, phenethyl alcohol had the highest flavor dilution (FD) factors ( $F D=2187$ ). Among the 88 components that were determined in terms of their odor activity values (OAVs), 35 compounds showed $O A V s \geq 1$. Furthermore, a reconstitution model was prepared by mixing the above mentioned 35 compounds, lactic acid, phenethyl alcohol and 2-methoxy-1,3dioxolane, and showed a good similarity to the aroma of Meilanchun baijiu. Omission/addition experiments further confirmed that ethyl hexanoate (OAV 1945), ethyl butanoate (OAV 838), 3-methyl-1butanol (OAV 2), 3-methylbutanal (OAV 618), methional (OAV 59), and dimethyl trisulfide (OAV 44), might be the most important compounds for the unique flavor of Meilanchun baijiu. In addition, phenols and acetoin (OAV 66) were confirmed to be the key odorants and the odorless compound lactic acid played a significant role in the roasted sesame flavor baijiu by the omission experiments.
\end{abstract}

\section{Introduction}

Baijiu is a kind of traditional alcoholic beverage in China, which has a long history, and is regarded as a pearl of ancient Chinese wisdom. Since the introduction of classification of baijiu flavor style in 1979, 12 major flavor styles of Chinese baijiu have been recognized. Among them, Jiang (soy sauce), Nong (strong), Mild (light), and $\mathrm{Mi}$ (rice) flavor styles are considered as the four basic flavor styles, while other flavor styles were considered to be derived from the aforementioned 4 basic flavor styles. For instance, sesame flavor style baijiu was derived from Jiang flavor style baijiu. The product possesses a unique style and complex aroma with roasted sesame flavor. ${ }^{1-3}$

There are some representative baijius with a sesame flavor, including Jingzhi, Bandaojing, Meilanchun, Baotuquan, etc.

${ }^{a}$ Beijing Advanced Innovation Center for Food Nutrition and Human Health, Beijing Technology and Business University, Beijing, China 100048. E-mail: huangmq@ btbu.edu.cn; Fax: +86-10-68984890; Tel: +86-10-68984613

${ }^{b}$ Beijing Key Laboratory of Flavor Chemistry, Beijing Technology and Business University, Beijing, China, 100048

${ }^{c}$ Department of Food Science and Human Nutrition, Clemson University, Clemson, SC 29634, USA
However, the whole flavor profiles of these baijius are different from each other. Liu et al. studied 12 sesame flavor style baijius by quantitative descriptive analysis, which included 8 aroma descriptions (i.e., sesame, baked, Chen-aroma, Jiang, strong, light, distilled grain, Qu-aroma), 3 taste descriptions (i.e., sweet, sour, bitter) and 5 mouthfeel descriptions (i.e., rich, soft, harmony, clean, aftertaste) to describe the sensory characteristics of these baijius. By the principal component analysis, the sesame flavor style baijius were further divided into 4 styles (pure sesame, partial strong, partial light, and partial Jiang flavor style), and the flavor profile expressed the quality difference of different sesame flavor style baijius. ${ }^{4}$

Meilanchun baijiu with sesame flavor (Meilanchun) was produced successfully by Ge Chongkai and Shen Yifang in 1985 according to a modified production process from Moutai liquor, one of the world's top three wines. The baijiu has a typical roasted sesame aroma and stable quality. ${ }^{5}$ In 1993, Jin Peizhang studied the components in Meilanchun and compared its characteristic components with those of other flavor style baijius, and the results showed that the contents of furfural, furfuralcohol, benzyl alcohol and 2,3-butanediol were high, which reflected some characteristics of soy sauce flavor style baijiu. ${ }^{6}$ The level of ethyl hexanoate was low, but had higher alcohols 
and isoamyl acetate. In 2012, Zhu Shuangliang compared the components of two Meilanchuns with other four famous baijius, and the results showed the amounts of 1,1-diethoxyethane, ethyl linoleate, ethyl oleate, ethyl palmitate, lactic acid and acetic acid were higher in Meilanchun than those of other baijius. In addition, its tetramethylpyrazine was 1.5-4.4 times of the same compound in other baijius with sesame flavor, but the content of butanoic acid was lower. ${ }^{7}$ Zhu Mengxu found that 1,1-diethoxymethane was not detected in all fresh liquors with the sesame flavor, but its content increased along with the aging process, as well as the great decrease of methanethiol, and both of them showed good correlations with the aging course. ${ }^{8}$ However, to the best of our knowledge, there is no report on the aroma-active compounds in Meilanchun up to now.

Sha Sha et al. investigated the aroma-active compounds in Jingzhi commercial baijiu with sesame flavor, and found 36 odorants had concentrations higher than their corresponding odor thresholds. For instance, 2-furfurylthiol (OAV 1182), dimethyl trisulfide (odor activity value, OAV 220), $\beta$-damascenone (OAV 116), and methional (OAV 99) could be responsible for the unique aroma of roasted sesame like flavor type liquor. Particularly, it was proposed that 2-furfurylthiol was the key typical potent odorant in the roasted sesame-like flavor type liquor by an omission test. ${ }^{9}$ Yang Zheng also studied the aromaactive compounds in two Jingzhi sesame flavor style baijius, and found 26 aroma compounds were further confirmed as the important odorants due to their OAVs $\geq 1$, and the omission experiments further corroborated the importance of ethyl hexanoate, 3-methylbutanal, ethyl pentanoate, methional and dimethyl trisulfide for the overall aroma of Jingzhi commercial baijiu. ${ }^{10}$ However, 2-furfurylthiol were neither found in the commercial baijiu nor in the base distillate. In addition, by direct injection combined with GC-MS, Sun et al. identified a total of 125 volatile compounds in 36 baijiu samples with the sesame flavor from 6 leading manufacturers. Among them, 30 volatiles, including two sulfur-containing compounds dimethyl disulfide and dimethyl trisulfide, were further identified as the active aroma compounds of Guojing sesame flavor style baijiu by the aroma extract dilution analysis (AEDA). ${ }^{11}$ Yet, 2-furfurylthiol was not found either. Therefore, it is questionable on the function of 2-furfurylthiol for the sesame flavor of Jingzhi baijiu, although 2-furfurylthiol has a typical sesame aroma and is often used as a food flavoring ingredient. Nevertheless, Meilanchun baijiu with a sesame flavor was selected and studied for this research according to the means of sensomics approach. ${ }^{\mathbf{1 2}}$

The aims of the present study were (i) to identify important odorants in Meilanchun sesame flavor style baijiu by GC-MS/O with AEDA, OAVs, recombination and omission/addition experiments, and (ii) to confirm the contribution of lactic acid for sesame flavor style baijiu.

\section{Materials and methods}

\section{Chemicals}

All chemicals were of analytical reagent grade, with at least 97\% purity. Ethyl acetate, ethyl 2-methylpropanoate, ethyl butanoate, ethyl 2-methylbutanoate, ethyl 3-methylbutanoate, ethyl pentanoate, ethyl hexanoate, ethyl lactate, diethyl butanedioate, ethyl propanoate, ethyl 4-methylpentanoate, 2methyl-1-propanol, 1-butanol, 3-methyl-1-butanol, 1-hexanol, acetic acid, butyric acid, 3-methylbutanoic acid, pentanoic acid, hexanoic acid, octanoic acid, decanoic acid, 3-methylbutanal, acetoin, phenethyl alcohol, phenyl acetaldehyde, ethyl phenylacetate, ethyl 3-phenylpropanoate, vanillin, 2,6dimethylpyrazine, 2,3,5-trimethyl pyrazine, guaiacol, 4-methylphenol, 4-ethylguaiacol, dimethyl trisulfide, methional, methionol, 1,1-diethoxyethane, ethyl nicotinate, 3-phenylpyridine, ethyl octanoate, hexyl acetate, propyl hexanoate, butyl hexanoate, hexyl hexanoate, ethyl nonanoate, ethyl decanoate, pentylhexanoate, ethyl 2-hydroxy-4-methylvalerate, ethyl heptanoate, isobutyl hexanoate, isopentyl hexanoate, ethyl dodecanoate, ethyl myristate, butyl butyrate, hexyl butyrate, diethyl octanedioate, ethyl hexadecanoate, 1-propanol, 1-heptanol, 1-octanol, propionic acid, pentanoic acid, heptanoic acid, nonanoic acid, ethyl benzoate, benzyl alcohol, acetophenone, benzaldehyde, 2-phenylethyl acetate, 2furfural, furfuryl alcohol, 2-acetylfuran, 5-methylfurfural, 2acetyl-5-methylfuran, tetramethylpyrazine, phenol, 4-ethylphenol, 2,4-di-tert-butylphenol, ethyl 3-methylthiopropionate, 1,1,3-triethoxypropane, $\gamma$-valerolactone, 3-(2-furyl)-2-propenal, $\alpha$-terpenol, nonanal, ethyl 2 -furoate, lactic acid, 3-phenylpyridine, 1,1-diethoxy-2-methylpropane, 2,3-diethyl-5methylpyrazine, 2-methoxy-1,3-dioxolane, ethyl acrylate, 2,3butandione, $\mathrm{C}_{6}-\mathrm{C}_{30} n$-alkane mixture, were purchased from Sigma-Aldrich Co., Ltd. (Beijing, China), J\&K Scientific Ltd. (Beijing, China), and Tokyo Chemical Industry Co., Ltd. (Shanghai, China). Dichloromethane, sodium chloride, anhydrous sodium sulfate, anhydrous ethanol, hydrochloric acid, sodium hydroxide were purchased from Sinopharm Chemical Reagent Co., Ltd. (Beijing, China). High purity nitrogen and high-purity helium (purity $\geq 99.999 \%$ ), were purchased from Beijing AP BAIF Gases Industry Co., Ltd (Beijing, China).

\section{Baijiu samples}

The commercial baijiu with sesame flavor product $37.0 \%$ vol, $500 \mathrm{~mL}$ ), provided by Meilanchun Company Limited, was stored at $4{ }^{\circ} \mathrm{C}$ prior to analysis. It is worthy of mention that the brand name did neither imply any of our research contact with the baijiu manufacturer, nor for advertising purpose.

\section{Isolation of the volatiles}

A total of $25 \mathrm{~mL}$ of Meilanchun commercial baijiu was diluted to $14 \%$ ethanol by volume with room-temperature boiled ultrapure water. The diluted baijiu sample was saturated with $\mathrm{NaCl}$, and extracted 3 times with freshly distilled dichloromethane (50 $\mathrm{mL}$ each time), then the organic phase extracts were merged to get the organic phase $\mathrm{O}_{1}$. Next, the organic phase $\mathrm{O}_{1}$ was extracted 3 times with an alkaline solution $(\mathrm{pH}$ $=10.0,50 \mathrm{~mL}$ each time), and separated to get the organic phase $\mathrm{O}_{2}$ and the merged water phase extracts $\mathrm{W}_{2}$. Then the $\mathrm{W}_{2}$ was adjusted to $\mathrm{pH}=2.0$ with hydrochloric acid solution of $2 \mathrm{~mol} \mathrm{~L}^{-1}$ and $1 \mathrm{~mol} \mathrm{~L}^{-1}$, and the solution was extracted 3 times with freshly redistilled dichloromethane $(50 \mathrm{~mL}$ each 
time) after being saturated with sodium chloride, and then the combined organic phase $\mathrm{O}_{3}$ was obtained. Organic phase $\mathrm{O}_{2}$ and $\mathrm{O}_{3}$ were dried over anhydrous $\mathrm{Na}_{2} \mathrm{SO}_{4}(30 \mathrm{~g})$ in $-20{ }^{\circ} \mathrm{C}$, then filtered, and the filtrate were concentrated to $\sim 500 \mu \mathrm{L}$ with using Vigreux columns followed by gentle stream of nitrogen. Finally the neutral/basic fraction (NBF) and acidic fraction (AF) of components in Meilanchun were obtained, respectively.

\section{Gas chromatography \& mass spectrometric/olfactometric (GC- MS/O) analysis}

GC-MS/O analysis was performed on an Agilent 7890 gas chromatograph, which was equipped with an Agilent 5975 mass detector and an olfactometer (ODP2, Gerstel, Germany). Samples were analyzed on two different fused silica capillaries, including DB-WAX $(60 \mathrm{~m} \times 0.25 \mathrm{~mm}$ i.d., $0.25 \mu \mathrm{m}$ film thickness, J\&W Scientific) and HP-5MS (30 $\mathrm{m} \times 0.25 \mathrm{~mm}$ i.d., $0.25 \mu \mathrm{m}$ film thickness, J\&K Scientific). The injector temperature was $250{ }^{\circ} \mathrm{C}$, and the splitless injection mode was used. The temperature of the olfactory port was kept at $220{ }^{\circ} \mathrm{C}$. Ultra-high purity helium (purity $>99.999 \%$ ) was used as the carrier gas at a constant rate of $1.5 \mathrm{~mL} \mathrm{~min}^{-1}$. An aliquot of $2.0 \mu \mathrm{L}$ of the concentrated samples (NBF and $\mathrm{AF}$ ) was analyzed by GC-MS/O.

DB-WAX column heating program: the oven temperature was held at $40{ }^{\circ} \mathrm{C}$ firstly, then raised to $50{ }^{\circ} \mathrm{C}$ at $10{ }^{\circ} \mathrm{C} \mathrm{min}^{-1}$ and held for $10 \mathrm{~min}$, then ramped to $80{ }^{\circ} \mathrm{C}$ at $3{ }^{\circ} \mathrm{C} \min ^{-1}$ and held for $10 \mathrm{~min}$, and finally increased at $5{ }^{\circ} \mathrm{C} \mathrm{min}^{-1}$ to $240{ }^{\circ} \mathrm{C}$, held for $7 \mathrm{~min}$.

HP-5MS column heating program: the oven temperature was held at $35{ }^{\circ} \mathrm{C}$ for $0.5 \mathrm{~min}$ firstly, then raised to $70{ }^{\circ} \mathrm{C}$ at $0.6{ }^{\circ} \mathrm{C} \mathrm{min}{ }^{-1}$ and held for $5 \mathrm{~min}$, then ramped to $230{ }^{\circ} \mathrm{C}$ at $5{ }^{\circ} \mathrm{C} \mathrm{min}{ }^{-1}$, and finally increased to $280{ }^{\circ} \mathrm{C}$ at $20{ }^{\circ} \mathrm{C} \min ^{-1}$ and held for $7 \mathrm{~min}$.

The mass spectrometer was operated in electron ionization (EI) mode at $70 \mathrm{eV}$, and the ion source temperature was $230{ }^{\circ} \mathrm{C}$. The mass-to-charge $(\mathrm{m} / \mathrm{z})$ ranged from 35 to 450 in full scan acquisition mode.

The sniffing experiments were performed by 3 experienced panelists (two females and one male). Before the experiments, they were trained by sniffing about 40 reference compounds in their concentrations 10 times above their odor thresholds in water or air. ${ }^{13}$ The identification of a compound was confirmed by comparing its mass spectra, retention time, odor quality and retention index (RI) with that of the corresponding reference compounds. All analyses were repeated in triplicate by each panelist.

\section{Aroma extract dilution analysis (AEDA)}

The flavor dilution factors of the active aroma compounds in the NBF and AF were determined by GC-MS/O on a DB-WAX capillary column. The two concentrated extracts of Meilanchun, NBF and AF, were diluted stepwise with dichloromethane in a series of $1: 3,1: 9,1: 27, \ldots$, until no scent was perceived. The flavor dilution factor of each compound was the maximum dilution in which the compound could be perceived.

\section{Quantitative analysis of aroma compounds}

The quantitation analysis of the volatile components was carried out on DB-WAX column, and their signal-to-noise ratios were required bigger than 10 .

Quantitative analysis by GC-MS. Baijiu sample was diluted by ethanol to $80.0 \%$ vol alcohol solution in order to reduced moisture content, and then $1.0 \mathrm{~mL}$ of the diluted sample added with $10.0 \mu \mathrm{L}$ internal standards solution was used for GC-MS analysis. The internal standard solutions were prepared as follows. The standard stock solutions were prepared with $80.0 \%$ vol ethanol solution. Then the different concentration standard solutions were obtained by diluting the stock solution step by step. Finally, $1.0 \mathrm{~mL}$ aliquots of these standard solutions were determined by GC-MS with selected-ion monitoring (SIM) mode. The standard curves were carried out by plotting the response ratios of standard compounds and internal standards against their concentration ratios.

The above diluted samples and different level standard solutions were spiked with the pivalic acid (IS1, $4.67 \mathrm{mg} \mathrm{L}^{-1}$ final concentration) and 2-ethyl butyric acid (IS2, $52.87 \mathrm{mg} \mathrm{L}^{-1}$ final concentration) as internal standards for acids, with methyl octanoate (IS3, $117.14 \mathrm{mg} \mathrm{L}^{-1}$ final concentration), methyl hexanoate (IS4, $1.1238 \mathrm{mg} \mathrm{L}^{-1}$ final concentration) and octyl propionate (IS5, $1.1429 \mathrm{mg} \mathrm{L}^{-1}$ final concentration) as internal standards for esters and other compounds. The internal standards with high concentrations were selected for the high concentrations of compounds in baijiu sample.

Quantitative analysis by headspace solid-phase microextraction-gas chromatography-mass spectrometry (HSSPME-GC-MS). The baijiu sample was diluted by saturated sodium chloride solution to $10 \%$ ethanol solution in volume. Then, $8 \mathrm{~mL}$ of the diluted solution with $10 \mu \mathrm{L}$ internal standards (IS4-2, methyl hexanoate, $73.75 \mu \mathrm{g} \mathrm{L}^{-1}$ final concentration; IS52, octyl propionate, $75 \mu \mathrm{g} \mathrm{L}{ }^{-1}$ final concentration) was poured into a $20 \mathrm{~mL}$ screw-capped vial. An automatic headspace sampling system (Multi Purpose Sample MPS2 with a solidphase microextraction (SPME) adapter, from Gerstel Inc., Mülheim, Ruhr, Germany) with a carboxen/ polydimethylsiloxane (CAR/PDMS $75 \mu \mathrm{m}$, Supelco, Inc., Bellefonte, PA, USA) was used to extract the volatile components. After the sample was preheated at $45{ }^{\circ} \mathrm{C}$ for $5 \mathrm{~min}$, the SPME fiber was inserted into the headspace and adsorbed for $40 \mathrm{~min}$ at $45{ }^{\circ} \mathrm{C}$. Then the SPME fiber was desorbed at $250{ }^{\circ} \mathrm{C}$ for $5 \mathrm{~min}$ in the injection port of GC-MS with a splitless mode. The flow rate of helium was $1.5 \mathrm{~mL} \mathrm{~min}^{-1}$, and the heating procedure was the same as the DB-WAX column analyzed by GC-MS/O. The GC-MS was used in selected-ion monitoring (SIM) mode.

The standard solutions on different levels were prepared by $10 \%$ vol alcohol solution, which was formulated with pure alcohol and the saturated sodium chloride solution, and then followed by an adjustment of their $\mathrm{pH}$ values with a dilute hydrochloric acid to the same $\mathrm{pH}$ of the corresponding baijiu sample. Then these standard solutions were analyzed by GC-MS as the above baijiu sample.

Quantitative analysis of lactic acid by liquid chromatography (LC). Because the content of lactic acid is very high in many 
baijius and probably has some contributions to the flavor of baijiu, it needs to be quantitated. However, lactic acid can be decomposed easily at high temperature, its content can not be measured by GC or GC/MS. Therefore, a high performance liquid chromatography (HPLC) (1260, Agilent Technologies, Inc., Santa Clara, CA) was used in our experiment.

The baijiu sample in a volume of $10.0 \mathrm{~mL}$ was evaporated and concentrated to $3-4 \mathrm{~mL}$ at $40{ }^{\circ} \mathrm{C}$ by a rotatory evaporator, and then the concentrated solution was added by ultra-pure water to $10.0 \mathrm{~mL}$ in total volume. Then the solution and a series of standard solutions of lactic acid were simultaneously analyzed by the same HPLC mentioned above. The standard solutions of lactic acid were prepared by ultra-pure water.

The LC conditions were as follows. Venusil XBP $\mathrm{C}_{18}(4.6 \mathrm{~mm}$ $\times 250 \mathrm{~mm}, 5 \mu \mathrm{m})$ was used and hold at $25{ }^{\circ} \mathrm{C}$. The variable wavelength detector worked at $205 \mathrm{~nm}$. The mobile phase was the mixture of methanol and potassium dihydrogen phosphate solution at the constant ratio $5: 95$ by volume. The concentration of potassium dihydrogen phosphate solution was $0.01 \mathrm{~mol} \mathrm{~L}^{-1}$ in water $(\mathrm{pH}=2.8)$. The flow rate was 1.0 $\mathrm{mL} \min ^{-1}$. The injection volume was $80.0 \mu \mathrm{L}$. Each samples was tested 3 times.

Determination of methionol and methional. The content of methionol and methional was measured by an external standard method and a liquid-liquid extraction followed by a GC-MS analysis, with the organic phase $\mathrm{O}_{1}$ from the above part of isolation of the volatiles as the analysis sample. The standard solutions of two sulfur-containing compounds were prepared with $37.0 \%$ vol ethanol solution. These different standard solutions were prepared as the above baijiu samples.

\section{Odor threshold determination and odor activity value (OAV) analysis}

The threshold values of components were mainly quoted from literatures, and other threshold values were determined in this study according to the literature.

Method of threshold determination. Based on the described method, ${ }^{\mathbf{1 3}, 14}$ the orthonasal thresholds of the odorants were determined by a forced-choice test at seven concentration steps. The proper high concentration of every odorant was firstly prepared with hydroalcoholic solution at $46 \%$ ethanol in volume, and then the solution was stepwise diluted $(1: 3$ by volume) with the same matrix to get 7 different concentration solutions for each odorant. Seven triangular series were prepared for every odorant, and each of them comprised of one glass of the odorant dilution and two glasses of hydroalcoholic solution. All of the series were labeled with random four-digit numbers and presented in decreasing concentrations. A sensory panel consisting of 25 panelists was asked to sniff and select a different one in each group of the triangular series. Then the two concentrations for every odorant were recorded, i.e. the minimum concentration that the assessors correctly selected and the maximum concentration incorrectly selected. Then, the odor threshold of each odorant was calculated by the following formula described in ref. 15.

$$
\mathrm{OT}_{\mathrm{i}}=\sqrt{C_{x} \times C_{x+1}}
$$

$\mathrm{OT}_{\mathrm{i}}$ : the individual recognition/detection odor threshold of each assessor; $C_{x}$ : the lowest concentration of the odorant, which was correctly selected by the assessor; $C_{x+1}$ : the highest concentration of the odorant, which was incorrectly selected by the assessor.

The recognition/detection odour threshold $\left(\mathrm{OT}_{n}\right)$ of the compound tested by the panel was calculated by the following formula ${ }^{15}$

$$
\mathrm{OT}_{n}=\sqrt[n]{\prod_{i=1}^{n} \mathrm{OT}_{\mathrm{i}}}
$$

$\mathrm{OT}_{n}$ : the recognition/detection odour threshold of the compound tested by a panel; $n$ : number of assessors; $\prod_{i=1}^{n} \mathrm{OT}_{\mathrm{i}}$ : the product of individual recognition/detection odor threshold.

Based on the quantitative results, odor activity value (OAV) of each substance was calculated as follows: OAV = the concentration of a compound/the odor threshold of the compound.

\section{Descriptive profile test}

The sensory evaluation of the Meilanchun sample was performed by10 trained panelists ( 5 males and 5 females, 24 years old on average). The Meilanchun sample in $30 \mathrm{~mL}$ was poured in an odorless tasting glass of Chinese baijiu, and the descriptive profile test was analyzed under $20 \pm 1{ }^{\circ} \mathrm{C} .{ }^{15}$ The assessors were asked to rank the intensities of 8 characteristic aroma attributes on a seven-point scale $(0,0.5,1.0,1.5,2.0,2.5,3.0)$ with 0 indicating not perceivable, 1 indicating weak, 2 indicating significant, 3 indicating strong. Eight characteristic aroma attributes and their responding references were as follows: roasted sesame seed for baked sesame note, acetic acid for acidic note, steamed grains including sorghum and rice husk for grain-like note, old pit mud for pit mud-like note, ethyl pentanoate for fruity note, 3-methylbutanal for malty note, 2methoxy-1,3-dioxolane for sweet note, ethanol for alcoholic note. After being trained, the overall aroma was evaluated for the Meilanchun baijiu by the panel.

\section{Aroma recombination experiments}

By using the odorants with OAVs $\geq 1$, phenethyl alcohol, 2methoxy-1,3-dioxolane and lactic acid, the complete aroma recombination models was prepared in $37 \%$ ethanol solution in pure water matrix (by volume), and their $\mathrm{pH}$ were adjusted to be same with Meilanchun. The aroma profiles of the recombination model were analyzed with the same method for Meilanchun.

\section{Omission experiments and addition experiments}

As the above odor threshold determination, a triangle test was performed to determine the significance of one odorant. A glass $(20 \mathrm{~mL})$ of the mixture was prepared by omitting or adding one or a group of selected components from the complete recombination models, and then presented with two glasses of 
Table 1 Aroma compounds identified by gas chromatography-mass spectrometry/olfactometry in Meilanchun sesame flavor style baijiu

RI

No. Compound Odor quality

Fruity, nail polish-like

Fruity

Fruity, nail polish-like

Plastic-like

Ethyl acrylate

Ethyl butanoate

Ethyl 2-methylbutanoate

Ethyl 3-methylbutanoate

Ethyl pentanoate

Ethyl 4-methylpentanoate

Ethyl hexanoate

Ethyl lactate

Diethyl butanedioate

Ethyl phenylacetate

Ethyl nicotinate

Ethyl 3-phenylpropanoate

Fruity, apple-like, strawberry-like

Fruity, apple-like, strawberry-like

Fruity, apple-like, strawberry-like

Fruity, apple-like, strawberry-like

Fruity

Fruity, fermented pear-like

Fruity

Sweet

Flowery, honey

Honey, sweet

Sweet

Fraction

Base of $\operatorname{Id}^{b}$

DB-WAX

HP-5MS

$\log _{3}$ FD

Malty, roast nuts-like

Malty, roast nuts-like

Malty, roast nuts-like

Green, flowery

Flowery

Fruity

Sweet, cake-like

Sweet, fruity

Sweet, fruity

Woody, roast nuts-like

Nutty, almond-like, buttery

Smoky, woody

Sour, vinegar-like

Sweaty, rancid

Sweaty

Sweaty

Sour, vinegar-like

Sweaty

Sour

NBF
NBF
NBF
NBF
NBF/AF
NBF
NBF
NBF
NBF
NBF/AF
NBF
NBF
NBF
NBF
NBF

$\mathrm{MS}, \mathrm{S}, \mathrm{O}, \mathrm{RI}$

MS,S,O,RI

$\mathrm{MS}, \mathrm{S}, \mathrm{O}, \mathrm{RI}$

$\mathrm{MS}, \mathrm{S}, \mathrm{O}$

MS,S,O,RI

$\mathrm{MS}, \mathrm{S}, \mathrm{O}, \mathrm{RI}$

MS,S,O,RI

MS,S,O,RI

MS,S,O,RI

$\mathrm{MS}, \mathrm{S}, \mathrm{O}, \mathrm{RI}$

$\mathrm{MS}, \mathrm{S}, \mathrm{O}, \mathrm{RI}$

MS,S,O,RI

MS,S,O,RI

$\mathrm{MS}, \mathrm{S}, \mathrm{O}, \mathrm{RI}$

MS,S,O,RI

910

954

946

976

1018

1036

1053

1118

1170

1215

1309

1661

1777

1819

1882

614

754

711

-

803

846

850

903

970

1005

820

1185

1247

1213

1351

$\mathrm{NBF} / \mathrm{AF}$

MS,S,O,RI

1076

$\mathrm{NBF} / \mathrm{AF}$

$\mathrm{MS}, \mathrm{S}, \mathrm{O}, \mathrm{RI}$

$\mathrm{NBF} / \mathrm{AF}$

$\mathrm{MS}, \mathrm{S}, \mathrm{O}, \mathrm{RI}$

$\mathrm{NBF}$

NBF/AF

MS,S,O,RI

1128

1191

1315

1906

623

658

733

865

1112

NBF

NBF

NBF

MS,S,O,RI

916

$\mathrm{MS}, \mathrm{S}, \mathrm{O}, \mathrm{RI}$

MS

1207

1402

NBF

MS,S,O

970

$\begin{array}{ll}726 & 5 \\ 927 & 6 \\ - & 3 \\ - & 3\end{array}$

$\mathrm{AF}$

MS,S,O

$\mathrm{MS}, \mathrm{S}, \mathrm{O}$

1289

NBF

$\mathrm{AF} / \mathrm{NBF}$

MS,S,O

1475

$\begin{array}{ll}- & 1 \\ - & 1 \\ - & 4\end{array}$

Stir-fried vegetable-like, sulfur

Cooked potato

MS,S,O,RI

1428

$\mathrm{MS}, \mathrm{S}, \mathrm{O}$

1610

$\mathrm{AF}$

MS,S,O

$\mathrm{MS}, \mathrm{S}, \mathrm{O}$

MS,S,O

MS,S,O

MS,S,O

600

$\mathrm{AF}$

$\mathrm{AF}$

$\mathrm{AF}$

1723

1830

2049

2271

$\begin{array}{ll}- & 4 \\ - & 4 \\ - & 2 \\ - & 3 \\ - & 1 \\ - & 3\end{array}$

Cooked potato

NBF

$\mathrm{NBF} / \mathrm{AF}$

MS,S,O,RI

1353

$\mathrm{MS}, \mathrm{S}, \mathrm{O}, \mathrm{RI}$

1434

968

905

980

7

NBF

MS,S,O,RI

1704

$\mathrm{MS}, \mathrm{S}, \mathrm{O}, \mathrm{RI}$

1849

Smoky, woody

Smoky

NBF

$\mathrm{MS}, \mathrm{S}, \mathrm{O}, \mathrm{RI}$

2024

1089

1280

1082

4
5
5

Butter-like

Malty, roast nuts-like

Honey

Caramel-like
$\mathrm{NBF} / \mathrm{AF}$

NBF/AF

$\mathrm{NBF} / \mathrm{AF}$

NBF

$\mathrm{AF}$
MS,S,O,RI

MS,S,O,RI

$\mathrm{MS}, \mathrm{S}, \mathrm{O}, \mathrm{RI}$

MS,S,O
960
921
1629
2582

604

648

1041 


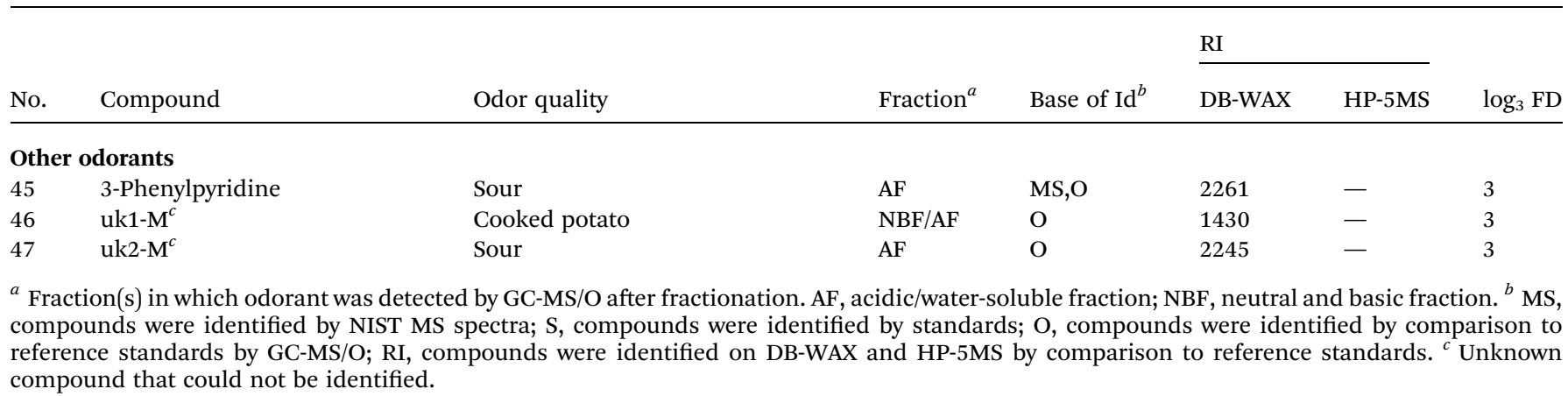

complete recombination models to the sensory panel in a triangle test. ${ }^{16}$ The sensory panel was the same as descriptive profile experiments. The significance $\alpha$ was calculated according to ref. 17. The sensory data were analyzed by one-way analysis of variance (ANOVA) by use of SPSS 20.0 (SPSS Inc., Chicago, IL, USA).

\section{Results and discussion}

\section{Analysis of aroma-active compounds in Meilanchun baijiu}

Ninety-two compounds were identified from NBF and AF, which were extracted from Meilanchun commercial baijiu. With GCMS/O, 47 odor-active peaks were detected, and 45 odor-active components were confirmed further, although two could not be identified yet. Besides, 35 odorants showed FD factors $\geq 9$, which were shown in Table 1 . The highest FD factors were determined for the ethyl pentanoate (8, fruity, apple-like, strawberry-like odor), ethyl 3-phenylpropanoate (15, sweet odor), 3-methyl-1-butanol (18, malty, roast nuts-like odor), phenylethyl alcohol (20, flowery odor), and methional (36, cooked potato odor) $(\mathrm{FD}=2187)$, followed by 3-methylbutanal (42, malty, roast nuts-like odor), ethyl butanoate (5, fruity, apple-like, strawberry-like), and 2-methoxy-1,3-dioxolane (22, sweet, cake-like odor) with FD 729. A majority of these odorants in Table 1 have also been reported as aroma compounds in other flavor type of Chinese baijiu. ${ }^{\mathbf{1 3 , 1 8}}$

Among the 45 odorants shown in Table 1 , there were 15 esters, 5 alcohols, 4 acetals, 3 pyrazines, 7 carboxylic acids, 3 sulfur-containing compounds, 3 phenols, 4 carbonyl odorants and 1 pyridine. The esters and acetals mainly contributed the fruity and sweet flavors to the Meilanchun baijiu, while the alcohols and 3-methylbutanal offered malty, roasted nut-like, the phenethyl alcohol contributed the flowery, the acids provided sour and sweaty, the phenols contributed the smoky, and methional offered cooked potato aromas. Pyrazines contributed some nutty and woody to the flavor of Meilanchun baijiu. The FDs of uk1-M (cooked potato) and uk2-M (sour) were 9 and 27 respectively.

\section{Concentration of compounds in Meilanchun baijiu}

In order to get deeper insight into the Meilanchun baijiu, a total of 90 detected compounds were quantitated (Table 2) by GC-MS or HPLC. Among these compounds, the content of ethyl acetate (808.66 $\mathrm{mg} \mathrm{L}^{-1}$ ) was the highest, followed by ethyl lactate (751.75 $\mathrm{mg} \mathrm{L}^{-1}$ ), acetic acid (711.08 $\mathrm{mg} \mathrm{L}^{-1}$ ), 3-methyl-1-butanol (249.72 $\left.\mathrm{mg} \mathrm{L}^{-1}\right)$, 2-methyl-1-propanol (158.23 $\left.\mathrm{mg} \mathrm{L}^{-1}\right)$, furfural (131.36 $\left.\mathrm{mg} \mathrm{L}^{-1}\right)$, hexanoic acid $\left(115.83 \mathrm{mg} \mathrm{L}^{-1}\right)$ and ethyl hexanoate $\left(107.62 \mathrm{mg} \mathrm{L}^{-1}\right)$. These 8 compounds were present at levels above $100 \mathrm{mg} \mathrm{L}^{-1}$, and were taken as the skeleton component (SC) of Meilanchun. Besides, the following compounds had higher concentrations, such as butyric acid (69.01 $\mathrm{mg} \mathrm{L}^{-1}$ ), ethyl butanoate (68.32 $\mathrm{mg} \mathrm{L}^{-1}$ ), 1-butanol (31.99 $\left.\mathrm{mg} \mathrm{L}^{-1}\right)$, pentanoic acid (23.98 $\left.\mathrm{mg} \mathrm{L}^{-1}\right)$, phenethyl alcohol (21.94 $\mathrm{mg} \mathrm{L}^{-1}$ ), 1,1-diethoxyethane (21.09 $\mathrm{mg} \mathrm{L}^{-1}$ ). The employed quantitative methods were able to detect all of the identified compounds in Meilanchun. The obtained calibration curves had good linearity with correlation coefficient $\left(R^{2}\right) \geq 0.99$; RSDs in triplicate of samples were $\leq 15 \%$, which revealed that the good precision of the quantitative methods.

Four kinds of carboxylic acids (lactic acid, acetic acid, hexanoic acid and butyric acid) are important to flavor in baijiu. All acids are volatiles except lactic acid which may usually ignored the contribution to baijiu aroma. Lactic acid in Meilanchun was quantitated by HPLC. Noteworthy the content of lactic acid was high (1754.67 $\mathrm{mg} \mathrm{L}^{-1}$ ) which may influence the aroma of Meilanchun.

\section{Odor activity values (OAVs)}

To overcome the shortcomings of GC-MS/O analysis with AEDA, ${ }^{19}$ and in view of ethanol concentration on the volatility of an odorant, ${ }^{20}$ the OAVs (ratio of concentration to its odor threshold) of the odorants were calculated to evaluate their contributions to the flavor of Meilanchun (Table 2). Besides, 13 odor thresholds determined in a mixture of ethanol/water (46/ 54 by vol) were used in this study.

The results in Table 2 showed there were 35 components with OAVs $\geq 1.0$ in Meilanchun, including 6 compounds undetected by GC-MS/O. They were ethyl octanoate (OAV 104), butyl hexanoate (OAV 1), 1-propanol (OAV 2), 4-methyl pentanoic acid (OAV 33), acetoin (OAV 66), 2-furfural (OAV 3). This showed that the influence of ethanol concentration on the volatility of an odorant. ${ }^{20}$ The OAVs of 7 compounds was greater than 100, which was ethyl hexanoate (OAV 1957), ethyl butanoate (OAV 833), 3-methylbutanal (OAV 638), ethyl 3- 
Table 2 Compounds' concentrations of in Meilanchun sesame flavor style baijiu

Meilanchun

\section{Aroma-active compounds in Meilanchun}

\section{Esters}

3

4

5

6

7

10

11

12

13

14

15

Alcohols$$
2
$$$$
3
$$$$
4
$$$$
5
$$$$
\text { Carboxylic acids }
$$$$
1
$$$$
2
$$$$
3
$$$$
5
$$$$
\begin{aligned}
& 5 \\
& 6
\end{aligned}
$$$$
6
$$

\section{Aldehydes and ketone}$$
2
$$$$
1
$$

Pyrazines

Phenols
Ethyl acetate ${ }^{a}$

Ethyl 2-methylpropanoate ${ }^{a}$

Ethyl butanoate $^{a}$

Ethyl 2-methylbutanoate ${ }^{a}$

Ethyl 3-methylbutanoate ${ }^{a}$

Ethyl pentanoate ${ }^{a}$

Ethyl hexanoate ${ }^{a}$

Ethyl lactate $^{a}$

Diethyl butanedioate $^{a}$

Ethyl propanoate

Ethyl 4-methylpentanoate

Ethyl phenylacetate

Ethyl 3-phenylpropanoate

Ethyl nicotinate

Ethyl acrylate

2-Methyl-1-propanol ${ }^{a}$

1-Butanol ${ }^{a}$

3-Methyl-1-butanol ${ }^{a}$

1-Hexanol ${ }^{a}$

Phenethyl alcohol $^{a}$

Acetic acid $^{a}$

Butyric acid $^{a}$

3-Methylbutanoic acid ${ }^{a}$

Pentanoic $\operatorname{acid}^{a}$

Hexanoic acid ${ }^{a}$

Octanoic acid ${ }^{a}$

Decanoic acid

3-Methylbutanal ${ }^{a}$

Phenyl acetaldehyde

Vanillin

2,3-Butanedione

$\begin{array}{ll}1 & \text { 2,6-Dimethylpyrazine } \\ 2 & \text { 2,3,5-Trimethylpyrazine } \\ 3 & \text { 2,3-Diethyl-5-methylpyrazine }\end{array}$

$\begin{array}{ll}1 & \text { Guaiacol } \\ 2 & \text { 4-Methylphenol } \\ 3 & \text { 4-Ethyl guaiacol } \\ \text { Sulfur-containing odorants } \\ 1 & \text { Dimethyl trisulfide } \\ 2 & \text { Methional } \\ 3 & \text { Methionol } \\ \text { Carbonyl odorants } & \\ 1 & \text { 1,1-Diethoxyethane }{ }^{a} \\ 2 & \text { Isobutyraldehyde diethyl acetal } \\ 3 & \text { 2,4,6-Trimethyl-1,3-dioxane } \\ 4 & \text { 2-Methoxy-1,3-dioxolane } \\ \text { Other odorants } & \\ 1 & \text { 3-Phenylpyridine } \\ 2 & \text { uk1-M } \\ 3 & \text { uk2-M }\end{array}$

Other compounds in Meilanchun

$\begin{array}{ll}1 & \text { Ethyl octanoate }^{a} \\ 2 & \text { Hexyl acetate }\end{array}$

$$
\begin{aligned}
& 808.66 \pm 6.3 \\
& 15.61 \pm 12.5 \\
& 68.32 \pm 4.5 \\
& 0.80 \pm 8.1 \\
& 2.78 \pm 6.1 \\
& 6.75 \pm 4.3 \\
& 107.62 \pm 9.1 \\
& 751.75 \pm 6.4 \\
& 1.33 \pm 7.5 \\
& 1351.71 \pm 10.3 \\
& 74.38 \pm 1.5 \\
& 497.78 \pm 6.8 \\
& 651.00 \pm 8.4 \\
& 95.44 \pm 5.4 \\
& 8.34 \pm 7.6 \\
& 158.23 \pm 5.0 \\
& 31.99 \pm 5.9 \\
& 249.72 \pm 4.0 \\
& 2.04 \pm 11.0 \\
& 21.94 \pm 6.8 \\
& 711.08 \pm 4.6 \\
& 69.01 \pm 4.4 \\
& 6.89 \pm 5.8 \\
& 23.98 \pm 4.3 \\
& 115.83 \pm 4.6 \\
& 7.48 \pm 5.4 \\
& 5571.81 \pm 9.9 \\
& 10.21 \pm 4.5 \\
& 61.33 \pm 15.6 \\
& 421.69 \pm 13.7 \\
& 8.67 \pm 12.03 \\
& 58.02 \pm 12.2 \\
& 91.10 \pm 6.1 \\
& - \\
& 20.93 \pm 15.6 \\
& 475.38 \pm 5.9 \\
& 250.75 \pm 6.4 \\
& 15.95 \pm 15.1 \\
& 422.20 \pm 10 \\
& 280.23 \pm 5.7 \\
& \\
& 21.46 \pm 8.6 \\
& \\
& \\
& \\
& \\
& \\
&
\end{aligned}
$$

$1.33 \pm 7.2$

$79.19 \pm 2.8$
32552 (ref. 21) 25

58 (ref. 21) 269

82 (ref. 21) 833

18 (ref. 23)

6.9 (ref. 21)

27 (ref. 21)

55 (ref. 21)

128084 (ref. 21)

353193 (ref. 21)

19019 (ref. 21)

1409

407 (ref. 21)

125 (ref. 21)

7781

0.2 (ref. 22)

44

403

250

1957

6

$<1$

$<1$

$<1$

1

5

$<1$

42

28300 (ref. 13)

2730 (ref. 21)

179191 (ref. 21)

5370 (ref. 13)

28923 (ref. 21)

160000 (ref. 13)

965 (ref. 21)

1045 (ref. 21)

389 (ref. 21)

2517 (ref. 21)

2701 (ref. 21)

13736 (ref. 21)

6

4

72

7

62

46

3

$<1$

16 (ref. 21)

262 (ref. 13)

438 (ref. 21)

5 (ref. 22)

638

$<1$

1

2

790 (ref. 21)

729 (ref. 21)

$<1$

$<1$

-

13 (ref. 21)

167 (ref. 21)

123 (ref. 21)

2

3

2

0.36 (ref. 21)

7.12 (ref. 23)

2110 (ref. 21)

44

59

$<1$

2090 (ref. 13)

10

-

-

19138

$<1$

-

12.87 (ref. 21)

104

5560 (ref. 24) 
Table 2 (Contd.)

\begin{tabular}{|c|c|c|c|c|}
\hline \multirow[b]{2}{*}{ Count } & \multirow[b]{2}{*}{ Compound } & Meilanchun & \multirow[b]{2}{*}{ Odor threshold ${ }^{c}\left(\mu \mathrm{g} \mathrm{L}^{-1}\right)$} & \multirow[b]{2}{*}{ OAVs } \\
\hline & & $\mathrm{AV}^{b} \pm \mathrm{RSD}(\%)$ & & \\
\hline 3 & Propyl hexanoate & $148.59 \pm 1.2$ & 12783 (ref. 21) & $<1$ \\
\hline 4 & Butyl hexanoate & $658.11 \pm 1.1$ & 678 (ref. 24) & 1 \\
\hline 5 & Hexyl hexanoate & $1166.35 \pm 2.1$ & 1890 (ref. 24) & $<1$ \\
\hline 6 & Ethyl nonanoate & $41.05 \pm 12.1$ & 3150 (ref. 21) & $<1$ \\
\hline 7 & Ethyl decanoate & $652.13 \pm 6.3$ & 1122 (ref. 21) & $<1$ \\
\hline 8 & Pentylhexanoate & $158.99 \pm 4.6$ & 13802 (ref. 25) & $<1$ \\
\hline 9 & Ethyl 2-hydroxy-4-methylvalerate ${ }^{a}$ & $12.73 \pm 6.8$ & - & - \\
\hline 10 & Ethyl heptanoate ${ }^{a}$ & $2.08 \pm 3.3$ & 13153 (ref. 21) & $<1$ \\
\hline 11 & Isobutyl hexanoate & $309.86 \pm 9.1$ & 5250 (ref. 25) & $<1$ \\
\hline 12 & Isopentylhexanoate & $166.66 \pm 6.6$ & 1400 (ref. 24) & $<1$ \\
\hline 13 & Ethyl dodecanoate & $354.51 \pm 12.8$ & 25619 & $<1$ \\
\hline 14 & Ethyl myristate & $221.93 \pm 7.5$ & 46606 & $<1$ \\
\hline 15 & Butyl butyrate & $672.24 \pm 5.2$ & 14066 & $<1$ \\
\hline 16 & Hexyl butyrate & $73.03 \pm 12$ & 30466 & $<1$ \\
\hline 17 & Diethyl octanedioate & $18.37 \pm 1.9$ & 641000 (ref. 23) & $<1$ \\
\hline 18 & Ethyl hexadecanoate & $123.77 \pm 11.5$ & 39299 & $<1$ \\
\hline 19 & 1-Propanol ${ }^{a}$ & $96.47 \pm 8.3$ & 53952 (ref. 21) & 2 \\
\hline 20 & 1- Heptanol & $138.19 \pm 12.1$ & 26600 (ref. 23) & $<1$ \\
\hline 21 & 1-Octanol & $119.53 \pm 5.6$ & 1100 (ref. 23) & $<1$ \\
\hline 22 & Propionic acid ${ }^{a}$ & $15.28 \pm 10.2$ & 18100 (ref. 23) & $<1$ \\
\hline 23 & 4-Methy pentanoic acid ${ }^{a}$ & $4.83 \pm 1.1$ & 144 (ref. 24) & 33 \\
\hline 24 & Heptanoic $\operatorname{acid}^{a}$ & $6.18 \pm 3.0$ & 13821 (ref. 21) & $<1$ \\
\hline 25 & Nonanoic acid & $3583.2 \pm 1.6$ & 3559 (ref. 21) & $<1$ \\
\hline 26 & Acetoin $^{a}$ & $17.00 \pm 2.0$ & 259 (ref. 23) & 66 \\
\hline 27 & Ethyl benzoate & $127.56 \pm 13.5$ & 1433 (ref. 21) & $<1$ \\
\hline 28 & Benzyl alcohol & $61.42 \pm 14.4$ & 40927 (ref. 21) & $<1$ \\
\hline 29 & Acetophenone & $8.65 \pm 16.6$ & 9474 & $<1$ \\
\hline 30 & Benzaldehyde $^{a}$ & $2.09 \pm 7.6$ & 4203 (ref. 21) & $<1$ \\
\hline 31 & 2-Phenylethyl acetate & $168.64 \pm 8.6$ & 908 (ref. 21) & $<1$ \\
\hline 32 & 2-Furfural ${ }^{a}$ & $131.36 \pm 7.7$ & 44029 (ref. 21) & 3 \\
\hline 33 & Furfuryl alcohol & $381.89 \pm 9.9$ & 12323 & $<1$ \\
\hline 34 & 2-Acetylfuran & $41.91 \pm 14.9$ & 58504 (ref. 21) & $<1$ \\
\hline 35 & 5-Methylfurfural & $124.80 \pm 13.6$ & 466321 (ref. 21) & $<1$ \\
\hline 36 & 2-Acetyl-5-methylfuran & $53.16 \pm 14.6$ & 40870 (ref. 21) & $<1$ \\
\hline 37 & Tetramethylpyrazine & $84.76 \pm 3.4$ & 80073 (ref. 21) & $<1$ \\
\hline 38 & Phenol & $64.30 \pm 9.5$ & 18900 (ref. 21) & $<1$ \\
\hline 39 & 4-Ethylphenol & $367.80 \pm 2.5$ & 617 (ref. 21) & $<1$ \\
\hline 40 & 2,4-Di-tert-butylphenol & $438.40 \pm 13.1$ & 36373 & $<1$ \\
\hline 41 & Ethyl 3-methylthiopropionate & $78.65 \pm 7.7$ & 3080 (ref. 25) & $<1$ \\
\hline 42 & 1,1,3-Triethoxypropane & $492.35 \pm 0.8$ & 3700 (ref. 23) & $<1$ \\
\hline 43 & $\gamma$-Valerolactone & $304.86 \pm 9.6$ & 25982 & $<1$ \\
\hline 44 & 3-(2-furyl)-2-propenal & $130.59 \pm 7.6$ & 13128 & $<1$ \\
\hline 45 & $\alpha$-Terpenol & $10.63 \pm 16.1$ & 1960 (ref. 25) & $<1$ \\
\hline 46 & Nonanal & $39.83 \pm 13.0$ & 122 (ref. 21) & $<1$ \\
\hline 47 & Ethyl 2-furoate & $131.23 \pm 5.5$ & 132000 (ref. 25) & $<1$ \\
\hline 48 & Lactic acid $^{a}$ & $1754.67 \pm 1.3$ & - & - \\
\hline
\end{tabular}

${ }^{a}$ The unit of concentration was $\mathrm{mg} \mathrm{L}^{-1}$, the unit of other compounds was $\mu \mathrm{g} \mathrm{L}^{-1}$. ${ }^{b}$ Average concentration of triplicates. ${ }^{c}$ Odor thresholds were determined in $46 \%$ ethanol/water solution according to our laboratory or references. ${ }^{13,21,22,23,24,25}$ reference numbers.

methylbutanoate (OAV 403), ethyl 2-methylpropionate (OAV 269), ethyl pentanoate (OAV 250) and ethyl octanoate (OAV 104). These components with OAVs $\geq 1.0$ should be important to the flavor of Meilanchun. There were 12 odorants with the OAVs between 10 and 100, such as ethyl hexanoate, ethyl butanoate and 3-methylbutanal. However, methionol, pyrazines and phenethyl alcohol had little effect on the aroma of Meilanchun because of their OAVs smaller than 1 .
In consideration of both FD values and the OAVs, it was found that some compounds with high FD value had relatively smaller OAVs. For example, the FD factors of phenethyl alcohol, 3-methyl-1-butanol and ethyl 3-phenylpropanoate possessed the largest FD values 2187, but their OAVs were low which indicated that the influence of the food matrix on odorant binding. ${ }^{19}$ 
Based on the OAVs in Table 2, esters (especially ethyl hexanoate and ethyl butanoate), alcohols, acids, 3-methylbutanal, phenols, dimethyl trisulfide, methional, and 1,1diethyoxyethane were considered to have important influence on the aroma of Meilanchun, which was basically in accordance with FD values and the reported results by Zheng et al. ${ }^{10}$ and Sha et al., ${ }^{9}$ especially the contributions of ethyl hexanoate, ethyl butanoate, 3-methylbutanal, dimethyl trisulfide, and methional to the aroma of roasted sesame flavor baijiu.

However, 2-furfurylthiol with a roasted sesame aroma reported by Sha et al. ${ }^{9}$ was not found in the study. According to the previous work, ${ }^{26,27}$ the odor of roasted sesame seeds was characterized by sulfurous, roasty, nutty, and meaty notes. The authors had not found a compound with a sesame-like flavor. The sesame-like flavor might be a composite flavor, and so there was probably no compound with sesame-like flavor.

\section{Descriptive profile and aroma recombination of Meilanchun}

To validate the quantitative results, the descriptive profile experiments were performed for the aroma recombinate in comparison to Meilanchun by rating the intensity of 7 odor attributes, as well as the overall similarity. The aroma recombinate was prepared in an ethanolic solution (37\%, ethanol by volume), and contained all important odorants with OAVs $\geq$ 1.0, phenethyl alcohol and 2-methoxy-1,3-dioxolane because of their high FD values, as well as lactic acid due to its high concentration. Besides, the $\mathrm{pH}$ in the aroma recombinate was adjusted to 3.9. The aroma descriptive profiles for Meilanchun and its simulation sample (M1) are shown in Fig. 1.

As shown in Fig. 1, a distinct sweet aroma quality was detected in Meilanchun, followed by acid, fruity, grain aroma, baked sesame-like, malty. The aroma of the recombinate had good similarities for sweet, fruity, grain-like, acidic, ethanol and pit mud-like, although the roasted sesame had some deficiencies. In addition, the floral note was very weak either in Meilanchun or in the recombinate, although a very strong

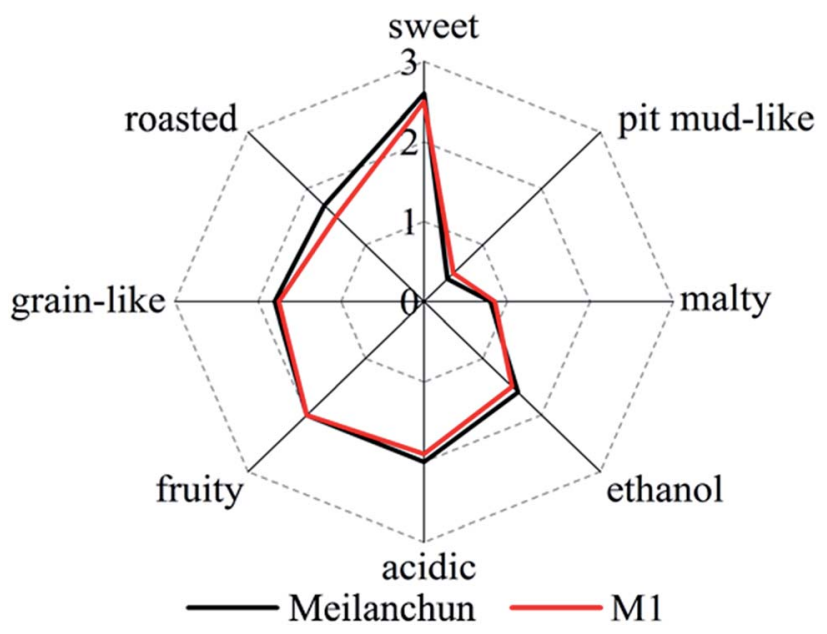

Fig. 1 Aroma descriptive profiles of Meilanchun sesame flavor style baijiu and its simulation sample with compounds of which OAVs $\geq 1$ (M1). floral aroma could be smelt during the GC-MS/O analysis. This implied that there were interactions among the odorants. ${ }^{\mathbf{1 9}}$ The overall aroma similarities between the recombination model and Meilanchun were judged to be 2.7 to 3.0 points and 2.8 to 3.0 points, respectively. These results indicated the successes in simulating the typical flavor of Meilanchun. This is the first time to study the flavor profile of Chinese baijiu.

\section{Omission and addition experiments}

To confirm the contributions of some key odorants to the flavor of Meilanchun, a total of 17 aroma omission and addition experiments were carried out, and each model was evaluated by a triangle test with the above complete recombination model. The results of omission and addition experiments were shown in Table 3.

The data in Table 3 showed there were very highly significant differences $(\alpha \leq 0.001)$ in the aroma of these omission models with comparison to the complete recombinate, such as esters, ethyl hexanoate, phenols, methional, and highly significant differences $(\alpha \leq 0.01)$ in the omission models of ethyl butanoate, acids, and dimethyl trisulfide. However, no significant difference was observed when ethyl lactate was omitted, or methionol was added. The results revealed that esters, phenols and acids were very important for the aroma of Meilanchun, especially ethyl hexanoate, methional, ethyl butanoate, and dimethyl trisulfide. The esters were mainly responsible for the typical fruity note of Meilanchun, but ethyl lactate has a little influence in spite of its relatively high level in Meilanchun, which were traditionally regarded as the most key aroma compounds because of their particularly high concentrations. ${ }^{28,29}$ The acids provided the acidic odor, and methional had an important contribution to the roasted note, and methionol contributed little to the Meilanchun aroma, which were in agreement with the reported by Zheng et al. ${ }^{\mathbf{1 0}}$ These phenols, such as guaiacol, 4-methylphenol and 4-ethyl guaiacol, were identified as key odorants at the first time for the roasted sesame flavor style baijiu.

The two model mixtures without 3-methylbutanal or 3methyl-1-butanol were also evaluated with significant differences $(\alpha \leq 0.05)$ in comparison to the complete reconstitution model. Besides, when the two compounds were omitted, the intensity of malty aroma decreased significantly, while the roasted note decreased slightly. Therefore, they were responsible for the malty aroma and part of roasted note in the entire model mixture.

As shown in Table 3, the omission of lactic acid or acetoin resulted in a significant difference $(\alpha \leq 0.05)$. When the mixture model was lack of lactic acid or acetoin, their aroma profiles had some changes in the softness or harmony. Therefore, lactic acid and acetoin (a mild creamy odor) could be as two blenders for the aroma of Meilanchun, since the creamy odor has good compatible with other odor note. This is the first time to confirm the effects of lactic acid and acetoin on the flavor of roasted sesame flavor baijiu.

In addition, the omission of phenethyl alcohol or compounds without odor threshold resulted in an 
Table 3 Omission and addition experiments from complete recombinate

\begin{tabular}{|c|c|c|c|c|}
\hline No. & Compounds & Category $^{a}$ & $n^{b}$ & Significance $^{c}$ \\
\hline $1-1$ & Esters & - & 10 & $* * *$ \\
\hline $1-2$ & Ethyl hexanoate & - & 9 & $* * *$ \\
\hline $1-4$ & Ethyl 2-methylpropanoate, ethyl 3-methylbutanoate, ethyl pentanoate, ethyl octanoate & - & 7 & $* *$ \\
\hline $1-5$ & Ethyl lactate & - & 3 & \\
\hline $2-1$ & Acids & - & 8 & $* *$ \\
\hline 3 & 3-Methyl-1-butanol & - & 8 & $*$ \\
\hline 4 & 3-Methylbutanal & - & 7 & $*$ \\
\hline 5 & Phenols & - & 9 & $* * *$ \\
\hline 6 & Dimethyl trisulfide & - & 8 & $* *$ \\
\hline 7 & Methional & - & 9 & $* * *$ \\
\hline 8 & Acetoin & - & 7 & $*$ \\
\hline
\end{tabular}

a "-", The compounds were omitted; “+”, the compounds were added. ${ }^{b}$ Number of correct judgments from 10 assessors evaluating the aroma difference by triangle test. ${ }^{c}$ Significance: ${ }^{*}$, significant $(\alpha \leq 0.05) ;{ }^{* *}$, highly significant $(\alpha \leq 0.01)$; ${ }^{* * *}$, very highly significant $(\alpha \leq 0.001)$.

insignificant difference from the complete reconstitution. Although phenethyl alcohol had a very high FD value, it had a little contribution to the aroma of Meilanchun because of its low concentration. This was different from the results of the roasted sesame flavor baijiu reported by Zheng et al. ${ }^{10}$ and Sha et $a .^{9}$

In conclusion, 92 compounds were identified from Meilanchun, 47 aroma-active compounds were detected by GC$\mathrm{MS} / \mathrm{O}$, including 45 identified aroma-active compounds and 2 unknown peaks, but 2 -furfurylthiol with the roasted sesame aroma was not found. In addition, 43 active odorants and 47 components without being smelt by GC-MS/O were accurately quantified by GC-MS. Meanwhile lactic acid was quantified by HPLC. There were 35 important odorants with OAVs more than 1. The aroma profile of Meilanchun sesame flavor style baijiu were successfully reconstituted by mixing 35 odorants with OAVs $\geq 1.0$, phenethyl alcohol, 2-methoxy-1,3-dioxolane, as well as lactic acid. The omission experiments further confirmed that ethyl hexanoate, phenols, methional were the key odorants making contributions to the overall aroma of Meilanchun baijiu, and ethyl butanoate, 3-methyl-1-butanol, 3-methylbutanal, acetoin and lactic acid also were important compounds to aroma. Methionol and phenethyl alcohol were not the characteristic odorants for Meilanchun sesame aromatype commercial baijiu. Further researches are needed to identify the function of 2-furfurylthiol for the sesame flavor style baijiu, and explore whether nonvolatile compounds have effects on its aroma, which may explain why the aroma simulation was weak in the roasted sesame aroma in ethanol/ water.

\section{Conflicts of interest}

The authors declare no competing financial interest.

\section{Abbreviations and nomenclature}

\author{
AEDA Aroma extract dilution analysis \\ OAVs Odor activity values \\ GC-MS/ Gas chromatography-mass spectrometry/ \\ O olfactometry \\ GC-MS Gas chromatography-mass spectrometry \\ IS Internal standard \\ AF Acidic fraction \\ NBF Neutral/basic fraction \\ FD factor The flavor dilution factor
}

\section{References}

$1 \mathrm{Q}$. Yu, The production processes of various flavor baijiu, in The Brewing Technology of Traditional Baijiu (Liquor), China Light Industry Press, Beijing, China, 2013, vol. 17, p. 69.

2 B. Sun, J. Wu, M. Huang, J. Sun and F. Zheng, Recent Advances of Flavor Chemistry in Chinese Liquor (Baijiu), $J$. Chin. Inst. Food Sci. Technol., 2015, 15, 1-8.

3 H. L. Liu and B. G. Sun, Effect of Fermentation Processing on the Flavor of Baijiu, J. Agric. Food Chem., 2018, 66, 5425-5432.

4 C. Liu, M. Liu, Q. Zhong, Z. Xiong, Z. Meng, L. Liu, Z. Lv and X. Li, Study on Typical Sensory Characteristics of Zhimaxiang Baijiu (Sesame-flavor Liquor) by Quantitative Description Analysis, Liquor-making Science \& Technology, 2014, (06), 10-15.

5 C. Gao, Formation and Innovation of Typical Styles of Meilanchun Sesame-flavor Liquor, Liquor-making Science \& Technology, 2010, (06), 101-107.

6 P. Jin, Analysis of aroma components from high quality Meilanchun Baijiu, Liquor-making Science \& Technology, 1993, (01), 62-65. 
7 S. Zhu, C. Gao and G. Cui, Analysis of Trace Compositions of Meilanchun Sesame-flavor Liquor, Liquor-making Science \& Technology, 2012, (06), 106-110.

8 M. Zhu, W. Fan, Y. Xu and Q. Zhou, 1,1-Diethoxymethane and methanethiol as age markers in Chinese roastedsesame-like aroma and flavour type liquor, Eur. Food Res. Technol., 2016, 242, 1985-1992.

9 S. Sha, S. Chen, M. Qian, C. Wang and Y. Xu, Characterization of the typical potent odorants in Chinese roasted sesame-like flavor type liquor by headspace solid phase microextraction-aroma extract dilution analysis, with special emphasis on sulfur-containing odorants, $J$. Agric. Food Chem., 2017, 65, 123-131.

10 Y. Zheng, B. Sun, M. Zhao, F. Zheng, M. Huang, J. Sun, X. Sun and H. Li, Characterization of the key odorants in Chinese Zhima aroma-style Baijiu by gas chromatography-olfactometry, quantitative measurements, aroma recombination, and omission studies, J. Agric. Food Chem., 2016, 64, 5367-5374.

11 J. Sun, D. Zhao, F. Zhang, B. Sun, F. Zheng, M. Huang, X. Sun and $\mathrm{H}$. Li, Joint direct injection and GC-MS chemometric approach for chemical profile and sulfur compounds of sesame-flavor Chinese Baijiu (Chinese liquor), Eur. Food Res. Technol., 2018, 244, 145-160.

12 L. Franitza, M. Granvogl and P. Schieberle, Characterization of the key aroma compounds in two commercial rums by means of the sensomics approach, J. Agric. Food Chem., 2016, 64, 637-645.

$13 \mathrm{~W}$. Gao, W. Fan and Y. Xu, Characterization of the key odorants in light aroma type Chinese liquor by gas chromatography-olfactometry, quantitative measurements, aroma recombination, and omission studies, J. Agric. Food Chem., 2014, 62, 5796-5804.

14 M. Czerny, M. Christlbauer, M. Christlbauer, A. Fischer, M. Granvogl, M. Hammer, C. Hartl, N. M. Hernandez and P. Schieberle, Re-investigation on odour thresholds of key food aroma compounds and development of an aroma language based on odour qualities of defined aqueous odorant solutions, Eur. Food Res. Technol., 2008, 228, 265273.

15 L. Poisson and P. Schieberle, Characterization of the key aroma compounds in an American Bourbon whisky by quantitative measurements, aroma recombination, and omission studies, J. Agric. Food Chem., 2008, 56, 5820-5826. 16 GB/T 10345-2007. Method of analysis for Chinese spirits.

17 G. Jellinek, Sensory Evaluation of Food. Theory and Practice, Ellis Horwood Ltd., Chichester, UK, 1985.
18 P. P. Wang, Z. Li, T. T. Qi, X. J. Li and S. Y. Pan, Development of a method for identification and accurate quantitation of aroma compounds in Chinese Daohuaxiang liquors based on SPME using a sol-gel fibre, Food Chem., 2015, 169, 230240.

19 P. Schieberle, New Developments in Methods for Analysis of Volatile Flavor Compounds and Their Precursors, in Characterization of Food: Emerging Methods, ed. A. G. Goankar, Elsevier, Amsterdam, The Netherlands, 1995, pp. 403-431.

$20 \mathrm{~W}$. Grosch, Aroma compounds, in Handbook of Food Analysis, ed. L. M. L. Nollet, edn 2nd, Marcel Dekker Inc., New York, 2004, vol. 1, pp. 717-746.

21 W. L. Fan and Y. Xu, Determination of Odor Thresholds of Volatile Aroma Compounds in Baijiu by A Forced-choice Ascending Concentration Series Method of Limits, Liquor Making, 2011, 38(04), 80-84.

22 G. A. Burdock, Fenaroli's Handbook of Flavor Ingredients, edn 5th, CRC Press, New York, Washington, D.C, 2005: vol. 411, p. 543.

23 H. Fan, W. Fan and Y. Xu, Characterization of key odorants in Chinese Chixiang aroma-type liquor by gas chromatography-olfactometry, quantitative measurements, aroma recombination, and omission studies, J. Agric. Food Chem., 2015, 63, 3660-3668.

$24 \mathrm{X}$. Wang, W. Fan and Y. Xu, Comparison on aroma compounds in Chinese soy sauce and strong aroma type liquors by gas chromatography-olfactometry, chemical quantitative and odor activity values analysis, Eur. Food Res. Technol., 2014, 239, 813-825.

25 Q. Zhou, Study on flavor compounds of sesame flavor liquor, Jiangnan University, Wuxi, Jiangsu Province, 2015.

26 H. Tamura, A. Fujita, M. Steinhaus, E. Takahisa, H. Watanabe and P. Schieberle, Identification of Novel Aroma-Active Thiols in Pan-Roasted White Sesame Seeds, $J$. Agric. Food Chem., 2010, 58, 7368-7375.

27 H. Tamura, A. Fujita, M. Steinhaus, E. Takahisa, H. Watanabe and P. Schieberle, Assessment of the Aroma Impact of Major Odor-Active Thiols in Pan-roasted White Sesame Seeds by Calculation of Odor Activity Values, $J$. Agric. Food Chem., 2011, 59, 10211-10218.

28 Y. Wang, Effects of the main trace components and its quantity relative ratio relationship of Fen-flavor liquor on the sensory quality, Liquor-making Science \& Technology, 2004, 3, 27-29.

29 Y. Shen, Manual of Chinese Liquor Manufactures Technology, Light Industry Publishing House of China, Beijing, China, 1996. 